\title{
An outbreak of calicivirus infection in a mother and baby unit
}

\author{
WD CUBITT,* DA MCSWIGGAN,* AND S ARSTALL $\dagger$ \\ From the *Public Health Laboratory and Department of Microbiology, Central Middlesex Hospital, \\ London NW10 7NS and †Shenley Hospital, Shenley, Herts, UK
}

SUMmaRY A small outbreak of infection due to a calicivirus occurred in a mother and baby unit. All the infants showed evidence of infection but the clinical features varied. None of the staff or mothers showed evidence of illness, and antibody studies indicated past experience of this virus.

The increasing use of electron microscopy in diagnostic virology has been a feature of the past decade. One of the results of this increased activity has been the demonstration of various viruses in stools, which it has not yet proved possible to propagate readily in cell culture or in animals. Some of these viruses are now well established as causes of gastroenteritis in man, while the status of others has not yet been adequately determined. Recently, evidence has been put forward that one such agent, apparently a human strain of calicivirus, is capable of producing gastroenteritis in man. ${ }^{1}$ We now report another outbreak which provides further evidence in support of the role of calicivirus in human infection.

\section{The outbreak}

The outbreak occurred between July and August 1979 in a mother and baby unit in a psychiatric

Received for publication 17 March 1980 hospital. The building was clean and well maintained and housed six mothers aged 19-33 years and their six infants aged 1-18 months. The infants slept in two nurseries separate from their mothers, but the recreation and toilet areas were communal. A nappy changing room was provided; this room was rather small and, when used simultaneously by several mothers, ample opportunity would exist for the transmission of virus by either the faecal-oral or respiratory route.

The clinical features of the illness varied widely among those shown to be infected (Table). Two infants had no clinical features of illness, and two had mild vomiting and diarrhoea lasting one day. On the other hand, the two remaining infants had an illness of considerable severity with repeated bouts of vomiting and diarrhoea lasting seven and nine days, respectively. Infant 1 , the most severely affected, had projectile vomiting; fever was recorded on four of the nine days of illness. It was this infant's illness that prompted the investigation. None of the six mothers or eight staff showed signs

Clinical and laboratory data on six infants and two staff members

\begin{tabular}{|c|c|c|c|c|c|c|c|c|c|c|}
\hline \multirow[t]{2}{*}{ Subject } & \multirow[t]{2}{*}{ Age } & \multicolumn{3}{|c|}{ Symptoms } & \multirow[t]{2}{*}{ Duration } & \multirow[t]{2}{*}{ Virus present } & \multicolumn{2}{|c|}{ Immune EM } & \multirow[t]{2}{*}{$I g G$} & \multirow[t]{2}{*}{$\operatorname{Ig} M$} \\
\hline & & $V$ & $D$ & $F$ & & & & & & \\
\hline Infant 1 & $18 \mathrm{mth}$ & $+t$ & + & + & 9 days & $+(8,10)-(11,12)$ & NA & NA & & \\
\hline 2 & $3 \mathrm{mth}$ & + & + & - & 1 day & $-(9)$ & $256(9)$ & $1028(16)$ & + & + \\
\hline 3 & $5 \mathrm{mth}$ & $+t$ & + & - & 7 days & $+(1,4,6)$ & 128(8); & $256(18)$ & + & + \\
\hline 4 & $4 \mathrm{mth}$ & + & + & - & 1 day & $+(2)$ & 64(2); & $512(9)$ & + & + \\
\hline 5 & $8 \mathrm{mth}$ & - & - & - & & $+(\mathbf{N K})-(\mathrm{NK}+5)$ & 512(NK); & $512(>9)$ & + & + \\
\hline 6 & $1 \mathrm{mth}$ & - & - & - & & $-(\mathrm{NK})$ & 64(NK); & $256(>40)$ & + & + \\
\hline Doctor & $31 \mathrm{yr}$ & - & - & - & & $-(\mathrm{NK})$ & 160(NK); & $160(>30)$ & + & - \\
\hline Nurse & $20 \mathrm{yr}$ & - & - & - & & & 20(NK); & $20(>30)$ & + & - \\
\hline
\end{tabular}

V D F = vomiting, diarrhoea, fever.

( ) indicates day after onset of symptoms.

NK $=$ not known.

$\mathrm{NA}=$ not available. 
of illness throughout the period of the outbreak. As routine bacteriological investigation of the specimens failed to provide an aetiological agent, they were then investigated by electron microscopy for a possible viral aetiology.

\section{Material and methods}

Specimens of stool were received from all the infants and from the doctor and the senior nurse. Acute and convalescent phase specimens of blood were obtained from five of the infants, the doctor, and the nurse. A single specimen of blood was obtained from each mother eight to 12 weeks after the incident.

The methods used for the preparation and examination of stools for electron microscopy and for antibody determinations were similar to those previously described. ${ }^{1}$ On this occasion the antigen used in antibody estimations was that obtained from infant 1 (see Table). Sponges of known capacity (see below) replaced filter papers for the collection of capillary blood. Blood was eluted from these sponges by placing each in an aliquot of $0.9 \mathrm{ml}$ of complement fixation test (CFT) buffer and repeatedly squeezing them over a period of 2 hours. This gave a final dilution of whole blood of $1 / 8$ (taken to be equivalent to a serum dilution of $1 / 16$ ). Venous blood was available from the adults.

The class of antibody present in the initial sample of blood in each case was determined using a blocking method. Aliquots of eluate from the sponges or $1 / 10$ dilutions of serum (venous blood) were mixed with an equal volume of sheep antihuman IgG or IgM (Wellcome Reagents) and incubated for 2 hours at $37^{\circ} \mathrm{C}$. Serial dilutions were made in CFT buffer and immunoelectron microscopy was performed overnight at $4{ }^{\circ} \mathrm{C}$.

The sponges used to collect capillary blood samples were reported to have a nominal absorption capacity of $0.1 \mathrm{ml}$ of blood. ${ }^{2}$ This was verified by weighing individually 10 sponges, immersing each in whole blood for 1 minute, and re-weighing; the increase in weight in grams was taken to represent the volume of blood in millilitres.

\section{Results}

The results are summarised in the Table. Typical calicivirus particles (Fig. 1), were detected on each occasion in stools from four out of six infants. Virus was detected in the stools of the two severely affected infants, 3 and 1 , on the sixth and tenth days after onset of symptoms, respectively. A third infant had virus in a single specimen collected on the second day of illness. The fourth child was found to

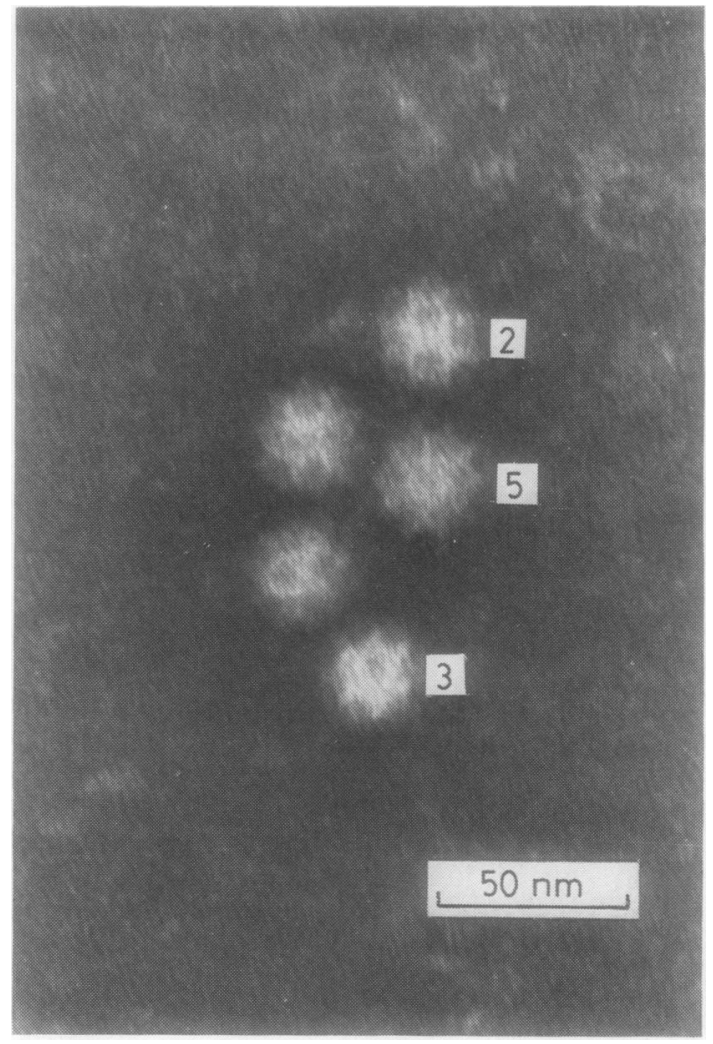

Fig. 1 Virus particles showing the 2, 3, and 5-fold axes of symmetry and corresponding morphology: $2=$ squareended cross; $3=$ star of David; $5=10$-pointed sphere. $\times 464000$

be excreting virus in an initial specimen but not in a second taken five days later. Calicivirus was not seen in the stools of the other symptomless infant nor in the single sample of stool from the other mildly affected child; however, in the latter case the specimen was obtained eight days after recovery. Virus was not seen in the stools of the doctor and nurse. The results of the antibody tests from the infants, doctor, and nurse are shown in the Table. An example of a test is shown in Figure 2. All five infants had antibody to calicivirus of the IgM class, indicating concurrent infection; three infants also showed fourfold or greater increase in antibody. The doctor and nurse had lower titres of antibody than the infants, showed no change between first and second samples, and had no IgM antibody to calicivirus. These results are consistent with past rather than concurrent infection with the virus.

All six mothers had antibody to calicivirus at titres ranging from 1 in 40 to 1 in 160 . It would not be expected that specimens taken two to three 


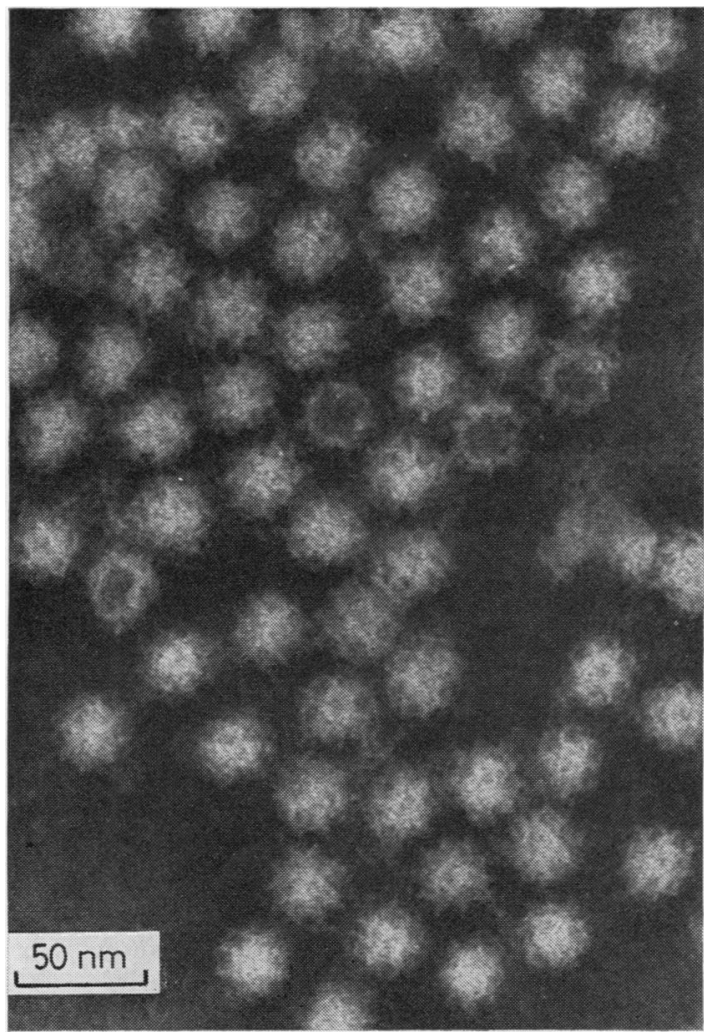

Fig. 2 Virus particles agglutinated by human serum. $\times 296000$.

months after an incident would have detectable specific IgM, the relatively low titres of the IgG specific antibodies in the mothers were on a par with those shown by the doctor and nurse and are, in our view, most likely to indicate a previous exposure predating the current incident.

Serum from a previous outbreak, which had previously shown a titre of 1 in 512 to homologous antigen, showed a titre of 1 in 128 to the virus from the current outbreak. (It was not possible to confirm the homologous serum and antigen titre in a parallel test due to lack of antigen.) The difference between the antibody titre to the current and former viruses is, in our opinion, unlikely to indicate a significant antigen difference.

Calibration of 10 sponges showed that each absorbed a mean volume of $0.125 \pm 0.019 \mathrm{ml}$ whole blood when fully expanded.

\section{Discussion}

This small incident goes some way to defining the spectrum of clinical presentation in infants resulting from infection with calicivirus. Two infants, clearly shown to be infected, showed no evidence of illness; two infants had mild symptoms of a type common in infancy and unlikely in normal circumstances to result in referral for medical examination let alone laboratory investigation. On the other hand, two of the infants were clearly unwell, one particularly so. The reason for this range of responses, as in many other infections, is not clear and may be due to a variety of features, including the dose of the infecting virus.

In a previous outbreak we commented on the rapid disappearance of virus from the stool. ${ }^{1}$ However, in that incident the affected children were older and had an illness of short duration. In the present incident the relatively prolonged excretion period found with the most severely affected child may indicate that the duration of virus excretion parallels the duration of the illness.

The presence of antibody to human calicivirus in all the adults examined is of interest. As far as we are aware, this has not previously been described, although antibody to animal calicivirus has been demonstrated in people working with such viruses. ${ }^{3}$ The absence of IgM antibody in specimens of blood from the doctor and nurse, taken at the time of the incident, is consistent with past experience of calicivirus and, although the evidence is less clear in respect of the mothers whose blood was not obtained until well after the incident, we are of the opinion that the antibody found in their sera also represents past infection. This would indicate a very high exposure rate to this agent by the time young adult age is reached. The mother of the 1-month-old infant had antibody to calicivirus. If, as we expect, this predated the outbreak, then her infant might be expected to have had transplacentally transmitted antibody to calicivirus. This infant was one of two who appeared to have a subclinical infection; calicivirus was not seen in a stool sample, but there was evidence of calicivirus specific IgM indicating an active infection. It might be expected that circulating antibody might not prevent direct infection of the bowel lumen via the oral route. On the other hand, indirect infection of the bowel wall via the respiratory route (and blood stream) seems less likely in the presence of circulating antibody. Thus this infant's infection may give some hint of the route of infection with this agent.

We described the previous outbreak as winter vomiting disease ${ }^{1}$ because it conformed reasonably well to Zahorsky's description of that disease. ${ }^{4}$ However, the current incident occurred at the height of summer, and such an epithet would be difficult to sustain. Indeed, the sporadic cases we have encountered indicate that this agent occurs 
throughout the year; whether a seasonal peak occurs remains to be demonstrated.

At present the 'human' calicivirus cannot be propagated in cell cultures, and there is, therefore, insufficient antigen to determine the biochemical characteristics of the virus. The features on which identification of the virus is based are restricted to size, buoyant density, and the distinctive surface morphology. The former two characteristics are shared with several other small viruses. The morphological features are, therefore, of paramount importance at least at the present time. In our experience, virus particles seen along each of the three distinct axes of symmetry 15 can be demonstrated, thus avoiding the need to rely on distinguishing one particular morphological form, such as the Star of David. ${ }^{6}$ Confusion with other viruses with a star morphology is then less likely to occur. In our experience, freezing and thawing of specimens destroys the distinctive viral morphology, and we, therefore, recommend that specimens be stored at $4{ }^{\circ} \mathrm{C}$. We have been able to detect the classical viral morphology in material held for more than a year at this temperature.

The recognised Caliciviridae, vesicular exanthema virus of pigs, San Miguel sealion virus, and feline calicivirus are not associated with bowel infection and are readily cultured in cells. The strain causing human bowel infection, on the other hand, conforms to the current 'rule' that those viruses causing gastroenteritis in humans cannot be readily cultivated. It is, therefore, of some interest that two new candidate animal caliciviruses, Newbury agent of cattle $^{7}$ and a porcine virus (Saif and Bohl, personal communication), both associated with gastroenteritis in their hosts, also appear to be refractory to cell culture. Presumably, there is some common key to the culture of all these gastroenteritis agents which still awaits discovery.

We thank Dr S Darougar for a supply of sponges and acknowledge the excellent secretarial assistance of Miss M Fielding.

\section{References}

${ }^{1}$ Cubitt WD, McSwiggan DA, Moore W. Winter vomiting disease caused by calicivirus. J Clin Pathol 1979;32:786-93.

${ }^{2}$ Darougar S, Treharne JD, Minassian D, El-Sheikh H, Dines RJ, Jones BR. Rapid serological test for diagnosis of chlamydial ocular infections. Brit J Ophthal 1978;62: 503-8.

${ }^{3}$ Smith AW, Prato C, Skilling DE. Caliciviruses infecting monkeys and possibly man. Am J Vet Res 1978;39:287-9.

4 Zahorsky J. Hyperemesis hiemis or the winter vomiting disease. Arch Paed 1929;46:391-5.

${ }^{5}$ Burroughs JN, Doel TR, Smale CJ, Brown F. A model for vesicular exanthema virus the prototype of the calicivirus group. J Gen Virol 1978;40:161-74.

${ }^{6}$ Madeley CR. Comparison of the features of astroviruses and caliciviruses seen in samples of faeces by electron microscopy. $J$ Inf Dis 1979;139:519-65.

${ }^{7}$ Woods GN, Bridger JC. Isolation of small viruses resembling astroviruses and caliciviruses from acute enteritis in calves. $J$ Med Microbiol 1978;11:441-51.

Requests for reprints to: Dr DA McSwiggan, Public Health Laboratory and Department of Microbiology, Central Middlesex Hospital, London NW10 7NS, UK. 